\title{
Co-application of red gypsum and sewage sludge on acidic tropical soils.
}

\begin{abstract}
The agroenvironmental impact of co-utilization of red gypsum and sewage sludge was investigated. Both laboratory and greenhouse studies were conducted. The treatments were soil + sewage sludge $(5 \% \mathrm{w} / \mathrm{w})+$ red gypsum $(0,2.5,5,10,20$, and $40 \%$, w/w $)$. Corn was grown in the greenhouse, and the highest rate of red gypsum application was excluded. The residual calcite in red gypsum was able to increase the $\mathrm{pH}$ of the red gypsum-sewage sludge acidic soil system. Hence, gypsum reduced the zinc (Zn) concentrations in the soil solution released by sewage sludge. Phosphorus $(\mathrm{P})$ and potassium $(\mathrm{K})$ were insufficient for corn growth. At the rate of $2.5 \%$ red gypsum and 5\% sewage sludge application, no dry-matter reduction was observed compared to the control. The uptake of $\mathrm{Zn}$, copper $(\mathrm{Cu})$, and iron (Fe) by the corn plants decreased. Therefore, co-utilization of red gypsum and sewage sludge is a better option than using these by-products separately.
\end{abstract}

Keyword: Acidic soils; Corn; Heavy metals; Red gypsum. 